\title{
Search for an optimal model for using online education in higher education in the context of sustainable digitalization
}

\author{
Alexander Dyatlov ${ }^{1, *}$, Vitaliy Kovalev ${ }^{1}$, and Alexey Kravets ${ }^{1}$ \\ ${ }^{1}$ Southern Federal University, Bol'shaya Sadovaya st. 105/42., Rostov-on-Don, Russia
}

\begin{abstract}
The relevance of the presented article is determined by the widespread use of online distance learning technologies in the educational space of higher education in Russia. This process is supported and initiated, among other things, by the modern Russian authorities, whose actions are based on the presumption of the ability of online education to provide the same quality of the educational process that takes place in the classroom-contact format. The authors ' hypothesis is based on the fact that the widespread introduction of online education cannot be evaluated positively, since its quality has not been tested empirically. Institutionalization should be carried out only after it is scientifically confirmed "where"," for whom"," by whom " online education can be implemented. For this purpose, the authors study the types of online education, its content, and assess the readiness of students to study online. The goal is formulated as determining the segments of the educational process in higher education in which online education will improve the quality of training of qualified specialists.
\end{abstract}

\section{Introduction}

For a long time, online education has been the stepson of the higher education system. And the attitude to it was formed accordingly, as to something exogenous, imposed from the outside, non-native. It should be noted that in the choice of means and setting goals, a certain amount of conservatism is actually characteristic of the professional activity of teachers. In part, this hinders progress, which makes it difficult to keep up with the changing social reality. Often, this hinders the satisfaction of new social needs, which leads to spontaneous processes of development of innovative forms in the educational system. However, the opposition to innovation also has a completely rational explanation. The new may not achieve the expected goals, but it is quite capable of destroying the old institutions. Therefore, the persistent unwillingness of teaching staff to use online technologies is not so much a manifestation of excessive conservatism, but rather the result of responsibility to society for the duties assigned to them. A certain balance should be built here. As a condition for achieving this goal, we consider gaining clarity about what online education is and in which segments of higher education it can be applied.

\footnotetext{
*Corresponding author: avdyatlov@yandex.ru
} 
Against the background of the outbreak of the pandemic, there is a surge of active interest in online education. Meanwhile, in science, and even more so in the rapidly and chaotically growing public discourse on this subject, there is no clear and clear understanding of what this new educational model is. There is no consistency even at the stage of naming the term. It is sometimes referred to as distance education, electronic education, and sometimes even distance learning. The inability to develop terminological boundaries during discussions objectively hinders understanding it in achieving the goals of the educational process. Even more negative consequences can occur if online education begins to be introduced on a permanent basis in the higher education system. Since the analyzed concept is filled with different, sometimes opposite meanings, it is not a priori able to perform the function of a universal trend towards digitalization of higher education under the guise of making it more progressive, and even more effective. Ambiguity in the problem statement will inevitably lead to the formalization of the task execution by the University management, and then to the mass reproduction of imitation practices and to the loss of social usefulness of the Institute of higher education.

Setting the problem in this capacity allows us to reach the formulation of the research goal. The goal can be defined as the definition of segments of the educational process in higher education, in which online education will improve the quality of training of qualified specialists.

So, to understand in which segments of the educational process online education can be effective, it is necessary to clearly define its content scope. Before we do this, we will consider the main trends that have developed in scientific discourse.

There are very few works aimed at analyzing the concept of online (distance, elearning) education. Even considering the fact that the tasks of solving terminological issues, as a rule, are auxiliary, secondary in nature.

Theoretical interest in online education originated in the context of studying the experience of distance education, seeking to understand its capabilities in connection with the application in the educational process new information and communication technologies (ICT). M. Han attempted to evaluate student's academic performance by their online learning patterns [1-6], M. Hung researched learners' readiness for online learning [7], J. Lee discovered that perception of e-learning quality depends on their self-regulatory efficacy [7-12]. S.S. Shah attempted to reveal the common online practices of students during COVID-19 pandemic [13-19], J. Rowsell and D. Alvermann were interested in how the digital divide influences online learning [20-25]. Works of F. Martin, T. Sun and C.D. Westine are of particular interest because of their attention to the accumulated results of online teaching and learning from 2009 to 2018 [26].

Researchers in Russian Federation are also interested in problems and prospects of online education and there are a significant amount of publications that demonstrate interest in this subject. Kirsanova E. V., and V. I. Chernenko under distance learning in the information society understand when "...a purposeful mediated interaction of the student and of the teacher is based on information technology, primarily with the use of telecommunications and television" [10]. S. E. Sayidova [18], A. A. Chigineva [3], V. Kamneva [9] in the analysis of the informative nature also pay attention to the mediated distances, the nature of the interaction between the student and the teacher, in the age of information technology provides a new and better opportunities. The adoption of the new law "on education" initiated the interest of researchers and practitioners in e-learning. It has become the subject of cognitive interest in the works of D. N. Mamatov [14], Yu. V. Navolochnaya [17], T. A. Vorobyova [24] and others. As a rule, researchers do not distinguish between distance and e-learning. It is also important to pay attention to the fact that online education is practically interpreted by specialists mainly as a synonym for distance and e-learning. However, one additional clarification needs to be made here: in its 
practical implementation, it is increasingly being identified with open online courses posted on commercial Internet sites, and mainly operating to meet the needs for additional education on a commercial basis [23]. The range of problems that specialists study is the availability of online education, its effectiveness, student motivation, advantages and disadvantages, and technical possibilities of implementation. Little has changed in the works of 2020, although against the background of the pandemic and the mass transfer of students from real audiences to virtual ones caused by it, the overall flow of publications on this topic has increased significantly. A typical indicator is the definition according to which "online education is a stable trend in modern society, allowing you to get an education literally" without leaving home"; it can be implemented in a number of educational programs and specialties " [22]. Such definitions characterize the current level of theoretical reflection on online education.

A common position among a number of specialists is that the concepts presented above are synonymous. Thus, A. A. Gorelova identifies online education as e-learning, joining the definition given UNESCO: "...it is learning through the Internet and multimedia" [4] R. S. Smirnov, D. V. Hablo and G. B. Dolgov online learning identified with the technologies that have emerged in the system of distance education and has resulted in the "emergence of new varieties of e - learning" [20]. B. J. Tagirov also of the opinion about the lack of fundamental differences between remote, electronic, and online learning. However, he does not provide the author's definitions in support of his position. But some researchers take a different approach, dividing the three analyzed concepts according to their semantic characteristics. N. V. Grechushkina begins to solve the problem by contrasting the concepts of distance and e-learning. In her opinion, distance education means education at a distance, while electronic education means using digital encoding of information and network resources for its placement [5]. The problem of differentiation of distance, e-learning and online education is posed by A. A. Strizhenko. In relation to the last two types, the author does not find any distinguishing features, referring to the fact that they are required to have an Internet connection and digital content. Distance education itself is probably regarded as an outdated concept since A. A. Strizhenko calls online education a modernized version of learning using distance technologies [21].

Most of the articles on online education are devoted to moocs. They are mostly complimentary in nature. It is rare, but there is also a negative attitude towards moocs. An example is the opinion of S. V. Bazhenov and E. Y. Bazhenova, according to which mooc platforms primarily of foreign origin, are a threat to Russia's national security, because "is a disguised form of promotion of corporate interests of transnational corporations, which ultimately will lead to the homogenization of higher education, the loss of academic freedom, the replacement of a significant number of faculty members on the so-called "superprofessional" (superprofessors) Tutors with excessively large office" [1].

In addition to moocs, there are other types of e-learning in the current discourse on online education. One of them is training in electronic teaching materials and videorecorded lecture courses, mainly purchased by regional universities from commercial agents of the Institute of higher education. This is a paid higher education resource created by the country's leading universities or business companies specializing in the production of educational services in the form of e-learning. The necessity of development of e-learning in the direction of the stresses O. V. Kalmykova [8], M. V. Kosolapova [11], A. V. Lisevich [13], N.E. Melnikova [15], Naletova I. V. [16], K. S. Chernysheva, O. V. Shirokova [2], and many other professionals who are in the digitalization of the educational system is primarily seen as a source of personal profit and not improving the quality of educational activities, or any other motives inherent in the traditional actors of the Institute of higher education. 
As you can see, the problem of online learning is extremely difficult for Russian science. The scientific community has not yet developed solidary ways of its institutionalization in the educational space of Russia. We can offer some aspects of this problem as conclusions in the final section of the study.

The analysis revealed several lacunae in the current discourse. First, there is a completely arbitrary use of the term "online education", mixing it with related concepts, which, of course, reflects the lack of theoretical work on the problem under analysis. Secondly, there is no work on the methodology of training in online education, which, of course, has its own pedagogical specifics and needs to be clarified. Both aspects are interrelated, since we proceed from the understanding that different educational models should be provided with methodological resources that correspond to their nature.

\section{Materials and methods}

An empirical study was conducted in May 2020. The main method is group interviews in student groups. A total of six group interviews were conducted. The respondents were students at the southern Federal University taking 1-2 courses in the areas of "Sociology", "Conflictology" and "Foreign regional studies". The sample consisted of 143 students. Since the guide included a fairly large number of questions, and the average number of groups exceeded 20 people, the average interview time was over three hours. To provide conditions for comfortable work, the survey was deliberately divided into two parts, so that it was possible to take a technical break. As for the group size exceeding the standard requirements, this problem was removed due to the social homogeneity of the group, as well as the presence of good contact with students from the moderator, who, at the same time, was a full-time teacher in each of the six groups. At the end of the survey, students were asked to write an essay on the topic " do I See the possibility of using online education in the educational process, and if so, in what part of it?" Since several students did not submit essays, the total number of them was less than the sample population - one hundred and thirty-seven units.

The described tools allow us to avoid arguments about the importance of the convenience of learning and its accessibility, focusing on positional advantages in ensuring the quality of educational services. When defining the indicators, we have abandoned the "quality" framework that is traditionally defined by the Ministry of science and higher education. Therefore, the guide does not contain questions about the availability of education, availability of classroom facilities, availability of elevators, interactive whiteboards, assessment funds, etc. All this is important, but these are only external conditions that provide the necessary comfort and tools. We turned to the universal competencies that are developed and implemented in the SFU University-wide educational standard. The competence-based approach of higher school teachers is well-deserved criticism, as it opens up space for unjustified formalization in the assessment of the educational process. However, in this case, it can be used as a conditional sample of quality, as an expected result, and the expectations themselves can be linked to students ' ideas about the comparative opportunities of online and classroom-contact education. At the same time, it was previously planned to interpret the possibilities of not just online education, but such established social practices as contact training in Teams and e-learning (moocs and classroom based on recorded training courses).

The main question of the group interview is formulated as follows: "What advantages and disadvantages of classroom-contact and online learning do You see for yourself in achieving high-quality results of your educational activities?". This question has the necessary potential to integrate through it all the coding categories developed in the process of operationalization of basic concepts. The aim of the study is to identify the segments of 
the educational process in higher education in which online education will improve the quality of training of qualified specialists. Therefore, it was important for us not only to establish the dispositional advantages and disadvantages of online education, but also to understand the weakest points of the classroom form of the educational process through the position of students.

\section{Results}

Before we proceed to evaluate the empirical data obtained, we first need to present the results related to the operationalization of basic concepts.

Online education should be considered as part of a more General process of digitalization of the economy. These are new technologies for transmitting information that facilitate the accessibility of its perception. However, online education is only an element of digitalization and can in no way overlap this global process of information revolution in the Institute of education. It is generally given too broad a meaning, while the scope of this term is much smaller. To justify this, let us turn to related concepts and show their terminological relationship with each other.

As a starting point, we will take three main terms: e-learning, distance learning, and online learning. They are used in the form of semantic units when describing the educational practices that have developed in the institutional space of higher education. As for these practices, there are also three types of them:: 1) synchronous (in a single time mode) interaction between the teacher and the student using telecommunications technologies (Teams or Zoom platforms); 2)listening to video lectures recorded by teachers of other universities in the audience and working in the computer room with electronic educational packages; 3) self-education using electronic information packages created by specialists for a specific training course (mass open online courses (moocs)). Each of these three forms is alternately referred to by specialists as distance, e-learning, or online learning. Because of this, online education itself turns into a completely incorrect term, which not only has an excessive and contradictory set of content features but is also used to describe completely different educational practices that solve different problems and even are located at different levels of the generally accepted typology of the type and form of education. For example, a mooc in accordance with paragraph 2 of part 1 of art. 17 of the Federal law "on education" can be attributed to an extra-organizational form of education as self-education, while simultaneously being a type of additional education; classroom classes, during which recorded lectures are shown, are defined as the use of distance technologies in the system of higher professional education; academic work in Teams or Zoom - does not differ qualitatively from the usual classroom, if we are talking about professional higher education, but can take completely different forms and adapt to the needs of any level (type) of education.

It is quite obvious that all these different educational practices cannot be explained under the cover of a single concept. Online education clearly needs a theoretical refinement.

The concept of e-learning is fixed in part 1 of article 16 of the Federal law on education. According to the current legislation, e-learning is carried out using information recorded on electronic media, delivered to students through the use of information and communication technologies. Distance education is defined in the same norm within the concept of "distance educational technologies". The Federal law on education calls its leading feature indirect (at a distance) interaction between students and teachers. This attribute means that it does not matter whether information technologies are used or not to characterize distance education. Their presence is only preferable from the point of view of the effectiveness of training, which is what the Law focuses on. The determining factor should be the distance between the teacher and the student. This understanding can be considered traditional, but it 
considers the changes in the educational environment that have occurred in the age of digitalization of the economy.

Let us demonstrate the results of an empirical study announced in the section "Materials and methods". To achieve the research goal, three out of ten encoding categories used in processing are important. They are specifically highlighted in italics below.

Education quality indicators and their variables. Perhaps the greatest interest and, accordingly, the longest duration of the discussions was caused by such an indicator as "mastering knowledge, skills and abilities". This is not surprising, since most students reflect on learning precisely as a process of mastering some information resources, which they then plan to use in the process of professional activity. Therefore, the problem at this stage of the discussion was to accept or reject online learning as a technological tool for mastering knowledge. The survey showed that there were 1-2 supporters of online education in each group. The main argument is: "anyone who wants to study will study in any format." Opponents of online education on average in groups were 5-6 people. There are three main arguments against:" there is no necessary environment where everyone is used to learning"," the presence of a teacher for learning is necessary, because he acts as an expert in mastering the material", "learning with live communication is more interesting and productive". Most of the participants in the groups behaved passively, but in front-line blitz surveys, positive statements about the ability of online education to provide highquality educational services were extremely rare. The remaining eight variables were discussed for a shorter period of time, as the level of consolidation within groups around the rejection of online education sharply increased and, accordingly, the subject for discussion disappeared. Only the indicator "formation of students 'motivation" caused an additional revival. Proponents of online education argued that the activity of teachers has a weak source of motivation, since the main impulse to learn should come from the students themselves. Therefore, the form of education does not affect the quality of education. Here, as additional arguments, the convenience of the online format was cited, which, all other things being equal, provided a greater attractiveness of online education in the views of this part of the participants.

Type of education and form of education. The discussion of these concepts was conducted in order to solve the following problem: to determine the place of online education in the Russian educational system. Most agreed that it has both specific and form-forming properties. Moocs are a separate subspecies of additional education, and work in contact online is its form for higher professional education. Except for 1-2 respondents, students were convinced that moocs will not be able to replace classical education, and work on Teams does not provide the necessary quality.

Hybrid education, problems of classroom-contact education, solving problems of classroom-contact education. Almost all respondents supported hybrid education, which includes elements of e-learning and "live work with a teacher in contact". Lecture classes received the most critical comments. Many of the students, even online opponents, offered to record them in video mode. There were no interesting opinions about solving the problems of classroom-contact teaching, which obviously shows the lack of awareness of students on this issue. Or, alternatively, it reveals a limited resource on this aspect of moderation of a group interview by a teacher.

The evaluation of the essays written by the participants of the discussion provided additional information. First, out of eleven active supporters of the online format (in the form of e-learning), six sharply reduced the categorical statements and concluded that it was necessary to switch to hybrid education. The rest of them did not change their negative attitude to classroom-contact education. Secondly, at least half of the students wrote in their essays that online education is the future, although they did not provide additional arguments. Whether this indicates that the transition to e-learning is not technically ready, 
or whether such statements reflect the stereotypes imposed on them about the modernity of online education, it is difficult to say now. This issue needs to be studied separately.

\section{Discussion}

Thus, e-learning is implemented through the reproduction of information recorded on electronic media and the use of ICT. Remote - distance-mediated interaction of subjects of the educational space with the desired, but not mandatory use of ICT resources. Let us assume that distance and e-learning relate to each other as General and individual.

Now let us compare the definitions of distance and e-education with the three practices highlighted above, which in the current discourse are classified as online education. We are talking about the educational process on the teams (Zoom) platform, collective viewing of video lectures in classrooms and mass open " online courses "(moocs). You can use different bases to classify them. But we will turn to the one that is laid down in the legislation. Thus, according to article 16 of the Federal law on education, the concepts of distance and e-learning are separated by such criteria as the form of interaction between the student and the teacher. If we start from this, then moocs and classroom work with watching video lectures should be considered separate types of e-learning, which are implemented in a remote format. Their classification as online education is erroneous. Unfortunately, the trend is such that any educational package packaged in a digital format is automatically evaluated as an online education resource. Below we will show the fallacy of this approach.

As for the third educational practice, which operates in most modern universities in the form of synchronous online (Teams or Zoom), even in its external manifestations, it differs significantly from the two forms of e-learning discussed above. It has several features that distinguish it from moocs and e-learning in the classroom without a teacher. Its obvious feature is the simultaneous presence in the information and communication space of the teacher and student. Moreover, one-time interaction is understood not as a particular aspect of pedagogical interaction, but as the dominant form of communication between the student and the teacher, during which information exchange and personal development of the student takes place, and in the presence of a dialogue - including the teacher. This very important point is ignored by researchers when formulating the definition of online education. Communication with distance learning takes place only in the spatial separation of the student and teacher, but the presence of synchronous contact does not allow us to consider online education only as distance learning, although it is carried out at a distance. For distance education, it is important to have an information intermediary, for which it was installed in the educational system at one time. At the same time, online education cannot be fully identified with e-learning, since its remote nature is implemented with the mandatory use of electronic means of communication, which, in fact, provide simultaneous communication between the subjects of the educational space. However, we cannot consider online education as a kind of electronic education. It differs from the latter in that the source of information for online interaction is a teacher, and not an electronic information carrier.

To understand all these dependencies, it is necessary to introduce another conceptclassroom-contact work of students with teachers.

In the Order of June 21, 2018. No.1166 "on amendments to the Regulations on contact work of students with a teacher at the southern Federal University" States that it can include classes of lecture and seminar type, group and individual consultations, admission of an exam and credit, practice management. From this list, it is clear that contact work covers a standard and familiar type of education. 
Thus, before making a typology of the analyzed types of education - distance, electronic, online and classroom-contact, we will determine the General basis for comparing the selected features. As such a basis, we will consider the established order of interaction between the teacher and the student.

Using this basis, we distinguish two forms of education: classroom-contact and distance education. Since the source of information in the e-learning system is a digitized version of educational content, it should be considered part of distance education. Since it has no common features with classroom-contact education, it is fully integrated into the content of distance education. As for online education, the situation here is more complicated. It is easy to see that it has substantial features that are characteristic of both distance and classroom-contact education. The presence of a territorial distance that occurs in teacherstudent communication demarcates the terminological boundary between online and distance education. But at the same time, online education has a common semantic field with classroom-contact education. It is formed through the interaction of teachers and students mediated by ICT resources. In such a model, there is a synchronous contact, even if it occurs in a digital environment. And what is of particular importance, this type of educational activity cannot be considered e-learning, since in it the leading information carrier is not an electronic source, but a teacher who comes into direct contact with the student.

The analysis of related concepts allows us to identify three leading properties of online education: interaction in a single time format, interaction at a distance, and interaction through information and communication technologies.

Now it is necessary to determine how independent the term is online education. In our opinion, it cannot be considered either distance, electronic, or classroom-contact education. This is a separate form of education, the elements of which can be integrated into a particular type of education (for example, additional or higher professional education). As a final definition, we can offer the following definition. Online education is a form of educational process that takes place in a remote mode of simultaneous interaction between the teacher and the student, which is provided through the use of information and telecommunications technologies.

\section{Conclusions}

Let us briefly summarize the results. We will start with the question. Do modern Russian higher education institutions need digitalization of the educational environment? Without a doubt, Yes. But it should be implemented with a clear understanding of the capabilities that it has, and with a correct statement of the tasks that it is able to solve. We have established that online education is a special form of organizing the educational process. In higher education institutions, it can only be used in limited locations: connecting students who are temporarily ill but do not want to miss classes, or people with disabilities to the educational process in a real audience; attracting world-class specialists to practical classes on a onetime basis; organizing students ' independent work; and organizing roundtables (if it is not possible to organize them offline). As for other aspects of educational activities, we consider it inappropriate to use the online format. Classical classroom-contact work provides greater efficiency in mastering educational programs. Unless, of course, efficiency is equated with cheapness and accessibility, as modern lobbyists do, popularizing e-learning in isolation from classroom-contact learning. Describing the latter, it should be noted that moocs and listening in the audience cannot be considered online education. This is elearning implemented as part of distance education. It, especially moocs, has shown its effectiveness as an additional commercial education, and only in this form can it be institutionalized in the higher education space. At the same time, a mooc provides good 
results only if two external conditions are met: the student has a basic higher education obtained in an audience-contact format, and the student has a strong internal motivation. An attempt to integrate this model into the primary level of higher professional education, especially in the bachelor's degree, will lead to a sharp drop in the quality of education. From this point of view, the idea of creating "online courses" in the curriculum should be taken negatively. Managers of educational programs create them, sacrificing the least valuable, from their point of view, subject. It is natural to raise the question of who needs these victims? Elements of e-learning are valuable in organizing students ' independent work. But here it is necessary to talk about the problems of motivation already among the teachers themselves, in the view of which students should engage in independent work on their own. As for listening to recorded video lectures in student auditoriums, the question of their expediency can be raised only in conditions of a shortage of teaching staff in lowstatus regional universities.

To digitalize the educational space of higher education, it is not necessary to destroy the historically established classroom-contact form. Of course, it is currently in a crisis, but it cannot be overcome with the help of online education. Overcoming the crisis is a separate research topic.

\section{References}

1. S. V. Bazhenov, E. Yu. Bazhenova, Mass online education and national security of Russia. Humanization of education, 6, 71-77 (2015)

2. K. S. Chernysheva, O. V. Shirokova, Online education as a successful form of Internet business. Scientific notes of the Tambov branch of ROSMU, 16, 63-69 (2019)

3. A. A. Chigintseva, Actual problems of distance learning. SKIF. Questions of student science, 3 , 10-13 (2018)

4. A. A. Gorelova, Technologies and trends of modern online education, 211-216 (Kazan, Citinvent Publ., 2019)

5. N. V. Grechushkina, Pedagogy of online courses. Problems of modern education, 4, 161-171 (2020)

6. F. Han, R. Ellis, Predicting Students' Academic Performance by Their Online Learning Patterns in a Blended Course: To What Extent Is a Theory driven Approach and a Data driven Approach Consistent? Educational Technology \& Society, 24(1), 191-204 (2021) doi:10.2307/26977867

7. M. Hung, C. Chou, C. Chen, A. Own, Learner readiness for online learning: Scale development and student perceptions. Computers \& Education, 55(3), 1080-1090 (2010) https://doi.org/10.1016/j.compedu.2010.05.004.

8. O. V. Kalmykova, Online training - higher education for all. Prospects for the development of information technologies, 19, 115-119 (2014)

9. V. V. Kamneva, Use of information and communication technologies in the higher education system. SKIF. Questions of student science, 3, 22-28 (2018)

10. E. V. Kirsanova, V. I. Chernenko, On the issue of distance education. Bulletin of the Association of Tourism and Service Universities, 3, 78-83 (2012)

11. M. V. Kosolapova, Business and online education. Simferopol: publishing house of IP Zueva, 56-58. (2018).

12. J. Lee, W. Lee, The relationship of e-Learner's self-regulatory efficacy and perception of eLearning environmental quality. Computers in Human Behavior, 24(1), 32-47 (2008) https://doi.org/10.1016/j.chb.2006.12.001

13. A.V. Lisevich, Key trends in the online education market. Saransk: IP Afanasyev, 151-154 (2019)

14. D. N. Mamatov, Electronic learning in education. Education through life, 13, $12-16$ (2015) 
15. N.E. Melnikova, Online education in optics of domestic and foreign higher schools. Bulletin of the state University of Dubna. Series "human and social Sciences", 4, 38-45 (2019)

16. I. V. Naletova, Changes in the education system under the influence of online technologies. Psychology and pedagogy journal Gaudeamus, 2, 9-13. (2015)

17. Yu. V. Navalochnaya, Features of control in e-learning. Pedagogy and psychology of education, 4, 51-54 (2014)

18. S.E. Sayidova, Distance learning and education, 6,103-107 (2014)

19. S.S. Shah, et all.: Online learning during the COVID-19 pandemic: Applying the selfdetermination theory in the "new normal". Revista de Psicodidáctica (2021). https://doi.org/10.1016/j.psicoe.2020.12.003

20. R. S. Smirnov, D. V. Khablo, G. B. Dolgova, Application of online technologies in modern education, Education and science in modern conditions, 3, 219-221 (2015)

21. A. A. Strizhenko, Online education: theory and practice. Economy. Profession. Business, 1, 7579 (2016)

22. T. B. Terekhova, Actual aspects of higher education development in online mode. Education and law, 5, 122-125 (2020)

23. S. V. Titova, Mass open online courses in Russian education: myth or reality? Bulletin of Moscow university. Linguistics and intercultural communication, 1, 53-65 (2016)

24. T. A. Vorobyova, On the issue of the concept of e-learning. Ideas and Ideals, 2, 143-152 (2014)

25. J. Rowsell, E. Morrell, D. Alvermann, Confronting the Digital Divide: Debunking Brave New World Discourses. The Reading Teacher, 71(2), 157-165 (2017)

26. F. Martin, T. Sun, C.D. Westine, A systematic review of research on online teaching and learning from 2009 to 2018. Computers \& Education, 159 (2020) https://doi.org/10.1016/j.compedu.2020.104009 